\title{
Analysis of a Stochastic Optimal Control for Pension Funds and Application to Investments in Lower Middle-Income Countries
}

\author{
Tolulope Latunde ${ }^{\mathrm{a}, *}$, Opeyemi Odunayo Esan ${ }^{\mathrm{a}}$, Joseph Oluwaseun Richard ${ }^{\mathrm{a}}$, Damilola Deborah \\ Dare $^{\mathrm{a}}$ \\ ${ }^{a}$ Department of Mathematics, Federal University, Oye-Ekiti, Nigeria
}

\begin{abstract}
One of the major problems faced in the management of pension funds and plan is how to allocate and control the future flow of contribution likewise the proportion of portfolio value and investments in risky assets. This work considers the management of a pension plan by means of a stochastic dynamic programming model based on Merton's model. The model is analysed such that the conditions of optimal contribution and investment in risky assets are determined and sensitized. The case study of Nigeria, Ghana, Kenya is considered for various periods in the model simulation. Thus, the volatility condition obtained is used to estimate the efficiency of some important parameters of the model.
\end{abstract}

Keywords: Pension, stochastic, control, risky asset, parameters

Article History :

Received: 26 November 2019

Received in revised form: 01 January 2020

Accepted for publication: 18 January 2020

Published: 19 January 2020

(C)2020 Journal of the Nigerian Society of Physical Sciences. All rights reserved. Communicated by: B. J. Falaye

\section{Introduction}

Pension is described as a sum of money paid regularly to a person who has come to the end of his normal working life, or an annuity paid regularly as a benefit due to his retirement (who no longer work because of age, disablement etc.). A pension plan is a method for a prospective retiree to transfer part of his or her current income stream towards a retirement income. Pension plans are classified into two categories: The Defined Benefit (DB) and Defined Contribution(DC) scheme. The DB pension plan is mostly preferred by pension members due to his ability to bear the risk to the pension fund manager, while on the other hand DC pension fund plan on the other hand, is more popularly preferred by the pension fund managers due to its ability to transfer the risk to the pension fund members. The

${ }^{*}$ Corresponding author tel. no: +2348032801624

Email address: tolulope. latunde@fuoye.edu.ng (Tolulope Latunde) last payment (benefit) given to the retiree is based on how the investment performed. In DC, the contributions are said to be fixed and the benefits depend on profits generated on the benefits of assets. The risk obtained from the fund management is born by recipients. It is not at all like the defined benefit plan whereby the benefits are typically identified with last salary cadre and the risk associated with financing is supposed by the sponsoring agent. The utilization of classical instruments as portfolio theory is reviewed [1-3].

The World Bank has historically classified every economy as low, middle, or high income. It now further specifies countries as having low-, lower middle-, upper-middle -, or highincome economies. The world Bank uses Gross National Income (GNI) per capita, in current U.S. dollars converted by the Atlas method of a three-year moving average of exchange rates,as the basis for this classification. It views GNI as a broad measure and the single best indicator of economic capacity and progress. The World Bank used to refer to low-income and 
middle-income economies as developing economies; in 2016, it chose to drop the term from its vocabulary, citing a lack of specificity. Instead, they now refer to countries by their region, income, and lending status.

The classification of countries is determined by two factors: A country GNI per capita, which can change with economic growth, inflation, exchange rates, and population. Revisions to national accounts methods and data can also influence GNI per capita. Classification threshold: The thresholds are adjusted for inflation annually using the Special Drawing Right (SDR) deflator. MICs have a combined population of five billion, or over $70 \%$ of the world's seven billion people, hosting $73 \%$ of the world's economically disadvantaged. Representing about one-third of global GDP, Middle-Income Countries (MICs) are a major engine of global economic growth. Three major Countries namely: Nigeria, Ghana and Kenya would furthermore be considered as a case study.

Looking at the report which classifies Nigeria as a lowerincome country it says in Sub-Saharan Africa, Middle-Income Countries (MICs) - with a Gross Domestic Income (GDI) per capita between US $\$ 1,026$ and US $\$ 12,475$ - are divided into upper-middle-income Countries (UMIs) and Lower Middle-Income countries (LMICs). It is noted that Nigeria falls under lowermiddle-income countries. As a nation, Nigeria is a high-income country and is very rich, However, when the earnings of its average citizens is considered, it could be seen as a low-income one and this is because a large percentage of its population is poor. Nigeria is indisputably a low-income country, The larger percentage of citizenry and invariably the workforce earn around $60 \$$ per month at minimum which may not be sufficient to cater for basic needs.

Ghana, at a per capita income of about $\$ 1,820$, is an MIC, but this classification masks wide gaps in infrastructural and human development. Ghana's position is at the lowest ebb of the lower-middle-income countries, What this means is that the country has only but transited by a small margin from a low-income to a middle-income economy status. Many development indicators are still in the state of a low-income country, yet to reflect Ghana's new status as an MIC. While it is agreed that the MICs are a very diverse group by size, population, income and development levels, Ghana's current position is too precarious for comfort. Rather than becoming complacent, Government and Ghanaian at large must use Ghana's lower-middle-income status as launchpad to propel the economy to the next level. African countries like Angola, Gabon, and Botswana have already risen to upper-middle-income status and share membership with the likes of Malaysia and South Africa. Such rising must be Ghana's aspiration.

Kenya is the economic, financial, and transport hub of East Africa. Kenya's real GDP growth has averaged over 5\% for the last decade. Since 2014, Kenya has been ranked as a lower middle-income country because its per capita GDP crossed a World Bank threshold. While Kenya has a growing entrepreneurial middle class and steady growth, its economic development has been impaired by weak governance and corruption. Although reliable numbers are hard to find, unemployment and under- employment are extremely high, and could be near $40 \%$ of the population. In 2013, the country adopted a devolved system of government with the creation of 47 counties, and is in the process of devolving state revenues and responsibilities to the counties. Agriculture remains the backbone of the Kenyan economy, contributing one-third of GDP. About $75 \%$ of Kenya's population of roughly 48.5 million work at least part-time in the agricultural sector, including livestock and pastoral activities. Over $75 \%$ of agricultural output is from small-scale, rain-fed farming or livestock production. Tourism also holds a significant place in Kenya's economy. In spite of political turmoil throughout the second half of 2017, tourism was up 20\%, showcasing the strength of this sector. Inadequate infrastructure continues to hamper Kenya's efforts to improve its annual growth so that it can meaningfully address poverty and unemployment. Kenya has also successfully raised capital in the global bond market issuing its first sovereign bond offering in mid-2014, with a second occurring in February 2018.

However, there is a need to consider the utilisation of pension funds allocation of these MICs on assets such that the wealth of the countries can be optimized.

The dynamic model can be used to calculate optimal asset allocation as it also takes change in the climate investment such as change in expected risk and returns, this model is also important for managing pension fund asset.The theory of risk and return is practically referred to as the income that was established in addition to any change in the market price of the investment. Carton articulated that returns are very core to any pension funds since it was shared among several members to the normal contributions [4].

Stochastic model is considered because it allows us to investigate fully the dynamics of the fund through time, The analysis and control of pension fund dynamics are getting increasingly important as members start to pay more attention to the security of promised benefit and as sponsoring employers become more concerned about the timing and stability of cash flows and this method. Merton pioneered the stochastic optimal control for solving continuous problems in asset management [2]. The Hamilton-Jacobi-Bellman (HJB) equation is a common method used by many kinds of research in solving problems from the dynamic programming under the real-world probability measure, [5]. Several authors have laid down analysis related to the stochastic control approach such as using stochastic dynamic programming to analyse the financial risk in a defined contribution (DC) pension scheme under Gaussian interest rate models by attempting is to find an optimal investment strategy, [6-11]. Likewise, several types of research have worked on utilising the mathematical approach in solving problems associated with Pension funds management, [11-14].

However, some experts have carried out researches on the sensitivity analysis to ascertain the behaviour of parameters in the formulation of the model such as in control problem of management of assets, transportation problems, pension schemes and so on. [15-18]

Thus, We investigate herein the application of the dynamic model for pension fund as optimization system that will ensure appropriate standard of living before and after retirement 
by discovering its explicit solutions using parameter sensitivity analysis and illustrating the solutions by utilizing a process which is reformed to an asset-liability model (ALM) as in [3].

\section{MODEL FORMULATION}

The dynamic model for pension fund management is reviewed herein and analysed [3].

The following variables and parameters used represented in Tables 1 - 2 are functions of time $t$. Parameters $\mathrm{r}, \phi, \sigma, g, I, \mu$ are constant.

Table 1: Definition of Variables

\begin{tabular}{|c|c|}
\hline Variables & Definition \\
\hline$X_{t}$ & Wealth(portfolio market value) \\
\hline$P_{t}$ & pension payments \\
\hline$C_{t}$ & contributions \\
\hline$H_{t}$ & investment in the risky asset \\
\hline$A_{t}$ & market value of the risky asset. \\
\hline
\end{tabular}

Table 2: Definition of Parameters

\begin{tabular}{|c|c|}
\hline$\mu$ & contribution growth rate \\
\hline$\phi$ & risk premium (positive) \\
\hline$r$ & risk free rate \\
\hline$g$ & pension growth rate \\
\hline$\sigma$ & volatility of the risky asset \\
\hline$I$ & discount rate \\
\hline
\end{tabular}

Source: Nigeria, Ghana and Kenya National Pension Commission (PenCom), 2016-2017 Annual Reports.

The two types of pension funds aggregated pension fund in this work where their growth rate $g$ and $\mu$ respectively we have:

$$
d P_{t}=g P_{t}
$$

$$
d C_{t}=\mu C_{t}
$$

We consider a situation of two types of assets consisting: a riskfree asset with return, $r$; and a risky asset with price $A_{t}$ which supports the Brownian motion, [3]. Risk-free rate is assumed constant;

Considering $\left(c^{*}, H^{*}\right)$ as the policy of optimal control and $x_{m}$ to represent the maximum wealth, we shall look into the two types of pension funds (benefit and contribution) of the financial management that forms the aggregated pension fund

$$
d A_{t} / A_{t}=(\phi+r) d t+\sigma d W_{t}
$$

where $r>0$ and diffusion $\sigma>0$ are constant, $W_{t}$ represents the standard Brownian motion defined. Suppose contributors do not wish to settle for higher contributions either now or in the nearest period which as its effect on their discount rate. We dominated the psychological discount rate I, Under the above conditions and assumptions, a reasoning pension fund manager will be willing to minimize:

$$
V=\int_{0}^{\infty} \exp (-I s) C_{s}^{2} d s
$$

But the optimal policy has to fulfil the given constraints: -payments of pension $P_{t}$

-value of $X_{t}$

Then we try to obtain the policy $\left(C_{t}, H_{t}\right)$ where $\mathrm{E}(\mathrm{V})$ is minimized under the given constraints.

Given that $C_{t}$ represents the contribution and $P_{t}$ represents the pensions paid per time (assuming continuous discounts). The variable which is represented by $X(t), t \geq 0$, is the adapted process that represents the aggregate of the wealth or the value of pension fund at time $t$. It is supposed that the activities start on the pension fund at period where $t=0$ with wealth $X_{0} \geq 0$. The wealth process is described by the equation:

$$
d X_{t}=H_{t} X_{t} \frac{d A_{t}}{A_{t}}+\left(1+H_{t}\right) X_{t} r d t+\left(C_{t}-P_{t}\right) d t
$$

The first term of the equation on the right is due to the risky asset and the second is due to the riskless asset and third represents the flow with respect to the balance of subscriptions (contributions) and payment of pensions (benefit). The above equation can be re-written by substituting equation (2) into (4)

$$
d X_{t}=\left[r X t+H_{t} X_{t}+C_{t} P_{t}\right] d t+H_{t} X_{t} d W_{t}
$$

And assumption is made that

$$
\begin{aligned}
& 0=\inf \left(e^{-I t} c^{2}+V_{t}^{\prime}+(r x+\phi h x+c-p) V_{x}^{\prime}+g p V_{p}^{\prime}\right. \\
& \left.+\frac{1}{2} V \prime_{x, x} x^{2} h^{2} \sigma^{2}\right)
\end{aligned}
$$

Using the equations above we have:

$$
2 r-I-\phi^{2} / \sigma^{2}>0
$$

Suppose $I=r$. This assumption becomes

$$
r-\phi^{2} / \sigma^{2}>0 \equiv \Omega
$$

By solving equation (1) - (5) we obtain a solution $2 r-I-$ $\phi^{2} / \sigma^{2}>0$, that is, by a sufficient high Porfolio volatility $(\sigma>$ $\phi / \sqrt{r})$.

Suppose $\mathrm{V}(\mathrm{t}, \mathrm{x}, \mathrm{p})$ represents the value function of the formulated problem, the with Bellman's equation, we have

$$
\begin{aligned}
& 0=\inf \left(e^{I t} c^{2}+V_{t}^{\prime}+(r x+\phi h x+c p) V_{x}^{\prime}+g p V_{p}^{\prime}\right. \\
& \left.+\frac{1}{2} V_{x, x}^{\prime \prime} x^{2} h^{2} \sigma^{2}\right)
\end{aligned}
$$

$x>0$ and $h>0$ been a constraints, Since The polynomial function of $\mathrm{h}$ and $\mathrm{c}$ in the bracket is satisfied by the optimal policy $\left(h^{*}, c^{*}\right)$.

$$
\begin{aligned}
& \phi x V_{x}^{\prime}+V_{x, x}^{\prime \prime} x^{2} h \sigma^{2}=0 \\
& 2 e^{I t} c+V_{x}^{\prime}=0
\end{aligned}
$$


Table 3: Numerical values relative with respective Countries

\begin{tabular}{|l|l|l|l|l|l|r|}
\hline Country & Period & \multicolumn{1}{l|}{$r$} & $\phi$ & $\sigma$ & $g$ & $\Omega$ \\
\hline Nigeria & $2016-2017$ & 10.14 & $6.77 \times 10^{5}$ & $6.12 \times 10^{5}$ & 12.0 & 8.9163 \\
\hline Ghana & $2016-2017$ & 21.46 & $2.12 \times 10^{7}$ & $6.39 \times 10^{7}$ & 15.7 & 21.3499 \\
\hline Kenya & $2016-2017$ & 8.51 & $2.30 \times 10^{7}$ & $3.16 \times 10^{7}$ & 10.2 & 7.9802 \\
\hline \hline
\end{tabular}

Table 4: Risk free rate $r$ vs volatility condition $\Omega$

\begin{tabular}{|l|l|}
\hline$r$ & $\Omega$ \\
\hline 5 & 3.7763 \\
\hline 10 & 8.7763 \\
\hline 15 & 13.7763 \\
\hline 20 & 17.7763 \\
\hline
\end{tabular}

That is to say

$$
\begin{aligned}
h^{*} & =\frac{\phi V_{x}^{\prime}}{V_{x, x}^{\prime \prime} x \sigma^{2}} \\
c^{*} & =-\frac{V_{x}^{\prime}}{2 e^{-i t}}
\end{aligned}
$$

Substituting the (11) and (12) in equation (8) gives:

$$
-\frac{1}{4} e^{I} t V_{x}^{\prime 2}+V_{t}^{\prime}+(r x-p) V_{x}^{\prime}+g p V_{p}^{\prime}-\frac{\phi^{2}}{2 \sigma^{2}} \frac{V_{x}^{\prime 2}}{V_{x, x}^{\prime \prime}}=0
$$

Suppose

$$
V(t, x, p)=e^{-I t} F(x, p)
$$

Thus, the equation that satisfies $\mathrm{F}$ becomes

$$
-\frac{1}{4} F_{x}^{\prime 2}+(r x-p) F_{x}^{\prime}+g p F_{p}^{\prime}-\frac{\phi^{2}}{2 \sigma^{2}} \frac{F_{x}^{\prime} 2}{F_{x, x}^{\prime \prime}}=0
$$

Equation (16) is homogeneous at variable $y=x / p$ for $F(y)$. Let

$$
F(x, p)=p^{2} f(x / p)
$$

then the differential equation satisfying $\mathrm{f}$ is given by

$$
-\frac{1}{4} f^{\prime 2}+(2 g-I) f+((r-g) y-1) f^{\prime}-\frac{\phi^{2}}{2 \sigma^{2}} \frac{f^{\prime} 2}{f^{\prime \prime}}=0
$$

We derive the solution by solving problem of the form:

$$
f(k)=A k^{2}+B k+C
$$

Identify A, B and C and find

$$
f(k)=\left(2 r-I-\frac{\phi^{2}}{\sigma^{2}}\right)\left(y-\frac{1}{r-a}\right)^{2}
$$

we obtain the final value function by substituting equation (17) into equation (15), i.e., F into $\mathrm{V}$, and by conjecture :

$$
V(t, x, p)=e^{-I t}\left(2 r-I-\phi^{2} / \sigma^{2}\right)(x-p /(r-g))^{2}
$$

Table 5: Risk premium $\phi$ vs the portfolio volatility condition $\Omega$

\begin{tabular}{|l|c|}
\hline$\phi$ & $\Omega$ \\
\hline $1.0 \times 10^{5}$ & 10.1133 \\
\hline $2.0 \times 10^{5}$ & 10.0332 \\
\hline $3.0 \times 10^{5}$ & 9.8997 \\
\hline $4.0 \times 10^{5}$ & 9.7128 \\
\hline
\end{tabular}

Table 6: Volatility of the risky asset $\sigma$ vs the portfolio volatility condition $\Omega$

\begin{tabular}{|l|l|}
\hline$\sigma$ & $\Omega$ \\
\hline $1.0 \times 10^{6}$ & 9.6817 \\
\hline $2.0 \times 10^{6}$ & 10.0254 \\
\hline $3.0 \times 10^{6}$ & 10.0890 \\
\hline $4.0 \times 10^{6}$ & 10.1114 \\
\hline
\end{tabular}

this domain $x_{m} \leq x$ shows the optimal policy to be zero contribution and there exists in the portfolio, no risky asset. By (10), (11) and (18), an optimal policy expression is given:

$$
\begin{aligned}
& h^{*}= \begin{cases}\left(2 r-I-\phi^{2} / \sigma^{2}\right)\left(x_{m}-x\right) & \text { if } x \leq x_{m} \text { if } x_{m} \leq x \\
0 & \end{cases} \\
& c^{*}= \begin{cases}\left(2 r-\beta-\lambda^{2} / \sigma^{2}\right)\left(x_{m}-x\right) & \text { if } x \leq x_{m i \mathrm{f}} x_{m} \leq x \\
0 & \end{cases}
\end{aligned}
$$

The condition $\sigma>\phi \sqrt{r}$ attest the constraints ( They have been applied, by [7] in the context of DC pension schemes) On h and $\mathrm{c}$ to be satisfied.

\section{Numerical Simulations}

World Bank classifies Nigeria, Ghana and Kenya amongst others as lower-middle-income countries in Africa. As a result, we select the three counties to utilise the pension data for the model verification and analysis which was obtained via MAPLE software.

We utilize the recent records of National Pension Commission(PENCOM) for each country such as their inflation, stock market prices, and interest rates. We also consider the volatility of the risky asset, risk-free rate, pension growth rate, risk premium and the volatility condition. Tables 3-6 represent the computational results derived from the available data.

\section{DISCUSSION}

The portfolio volatility $2 \mathrm{r}-\mathrm{I}-(\phi / \sigma)^{2}>0$ need not to be met, since the investments do not achieve a convincing returnto-risk ratio. 


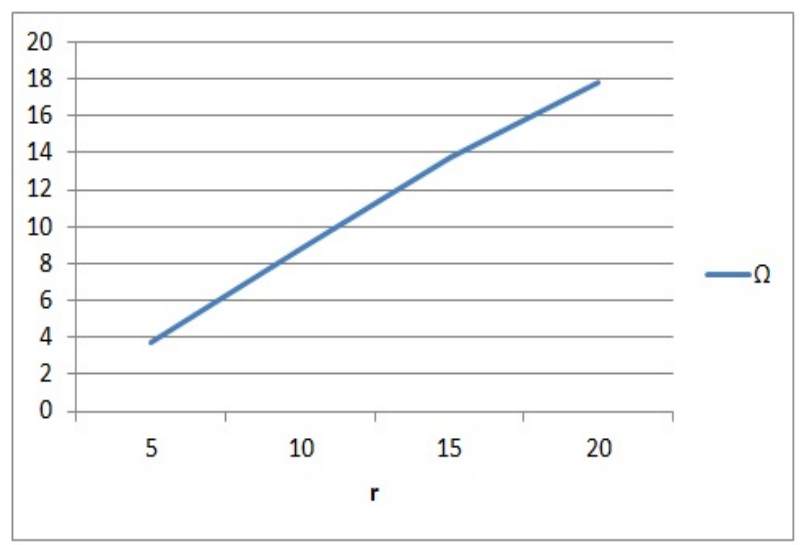

Figure 1: Graph of the volatility of risk-free rate $r$ against volatility condition $\Omega$

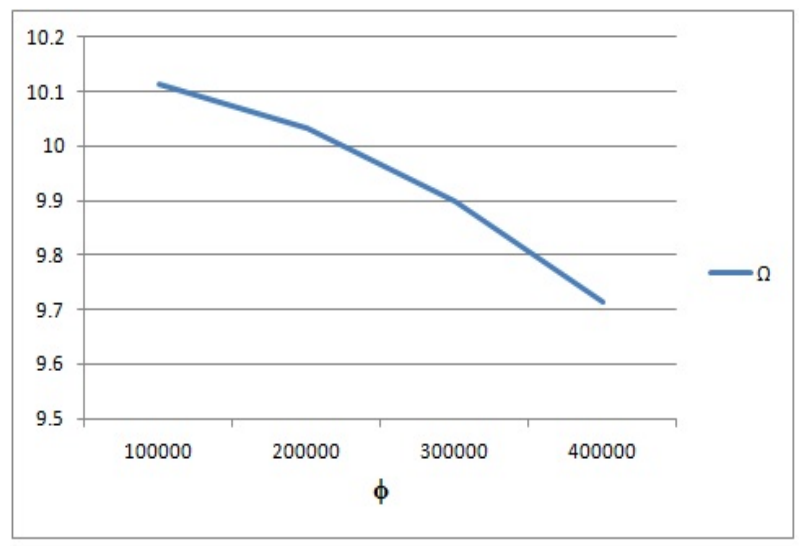

Figure 2: Graph of risk premium $\phi$ against volatility condition $\Omega$

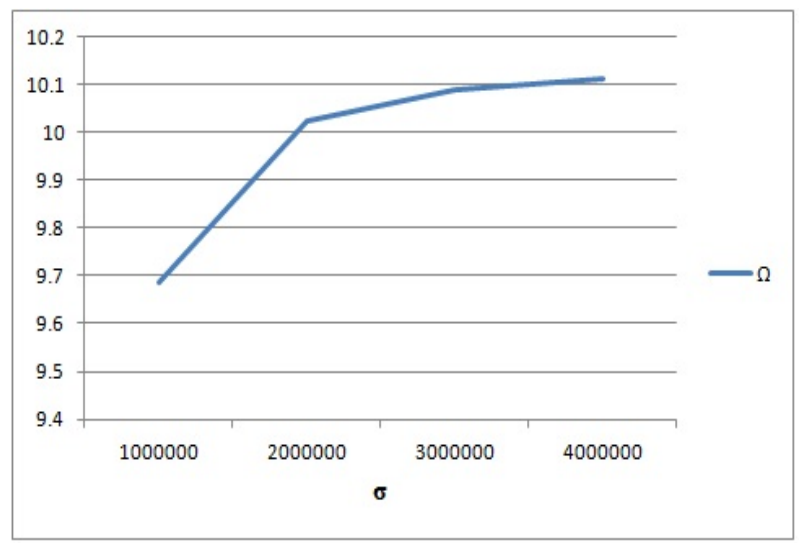

Figure 3: Graph of the volatility of the risky asset $\sigma$ against volatility condition $\Omega$

However, by using the Nigeria pension portfolio as a case study, the behaviour of some parameters in the model formulation is examined such that the effect of changes and estimation on each parameter on the derived volatility condition is determined and represented in the Figures 1 - 3 below plotted using Excel.

In this work, we applied a dynamic model of pension man- agement to real-life situations where a volatility condition was obtained alongside the optimal controls to determine the behaviours of the parameters of the model. The behaviour of some parameters of the model such that the effect of changes of the estimation of the values of each parameter on the derived volatility condition is determined and represented using Tables and Graphs. From Figure 1, we determined that the higher the volatility of the risk-free rate $r$, the higher the volatility condition $\Omega$. Also from Figure 2, we determined that the lower the risk premium $\phi$, the higher the volatility condition $\Omega$. From Figure 3, we also determined that the higher the volatility of the risky asset $\sigma$, the higher the volatility condition $\Omega$.

Hence, we can verify that the volatility condition $\Omega$ implies that the risk premium can be justified by high volatility. This justifies some logical reasoning aiding decision making in pension management.

\section{CONCLUSION}

In this work, we applied a dynamic model of pension management to real-life situations where a volatility condition was obtained alongside the optimal controls to determine the behaviours of the parameters of the model. This justifies a logical some logical reasoning aiding decision making in pension management.

In future works, stochastic analysis of such models can be carried out considering a wider range of data depending on countries from different continents. Likewise, a more analytic approach of the sensitivity analysis can be considered using more sophisticated software in solving and representing data and graphs of the new results.

\section{REFERENCES}

1. R. C. Merton "Lifetime portfolio selection under uncertainty: The continuous time case", Review of Economics and Statistics, 51 (1969) 247.

2. R. C. "Merton Optimal consumption and portfolio rules in a continuous time model",Journal of Economic Theory 42 (1971) 373.

3. J. F. Boulier, E. Trussant \& D. Florens "A dynamic model for pension funds management", Proceedings of the 5th AFIR International Colloquium 1 (1995) 361.

4. B. Carton, Measuring organizational performance:an exploratory study, A dissertation submitted to the graduate faculty of the university of Georgia, 2004.

5. M. Assellaou, Hamilton Jacobi Bellman approach for some applied optimal control problems, Mathematics Ensta Paris Tech, 2015.

6. T. E. Duncan \& B. Pasik-Duncan "A direct method for solving stochastic problems", Communications in Information Systems 12 (2012) 1.

7. E. Vigna \& S. Haberman "Optimal investment strategy for defined contribution pension schemes", Insurance: Mathematics and Economics 28 (2001) 233. 
8. P. Battocchio \& F. Menoncin "Optimal pension management in a stochastic framework", Insurance: Mathematics and Economics 34 (2004) 79.

9. F. Menoncin \& E. Vigna "Mean-variance target-based optimisation for defined contribution pension schemes in a stochastic framework", Insurance: Mathematics and Economics 76 (2017) 172.

10. A. Cairns \& G. Parker "Stochastic pension fund modelling",Insurance Mathematics and Economics 21 (2000) 43.

11. B. O. Osu "The price of asset-liability control under tail conditional expectation with no transaction cost", British Journal of Mathematics and Computer Science 1 (2011) 129.

12. A. Cairns, D. Blake \& K. Dowd "Stochastic lifestyling: Optimal dynamic asset allocation for defined-contribution pension plans", Journal of Economic Dynamic and Control 30 (2006) 843.

13. G. Deelstra, M. Grasselli, \& K. Pierre-François "Optimal investment strategies in the presence of a minimum guarantee", Insurance: Mathematics and Economics 33 (2003) 189.
14. R. Gerrard, S. Haberman \& E. Vigna "Optimal investment choices post retirement in a dened contribution pension scheme", Insurance: Mathematics and Economics 35 (2004) 321.

15. M. Latkovic, \& I. Liker "Sensitivity analysis of accumulated savings in a defined contribution pension system", Financial Theory and Practice 33 (2000) 431.

16. T. Latunde, O. M. Bamigbola \& Y. O. Aderinto, "Sensitivity of Parameters in an Optimal Control Model of the Electric Power Generating System", Ilorin Journal of Computer Science and Information Technology (ILJCSIT) 1 (2016) 54.

17. T. Latunde \& O. M. Bamigbola "Parameter Estimation and Sensitivity Analysis of an Optimal Control Model for Capital Asset Management", Advances in Fuzzy Systems, (2018) 1. https//doi.org/10.1155/2018/4756520

18. T. Latunde, J. O. Richard, O. O. Esan \& D. D. Dare "Sensitivity of Parameters in the Approach of Linear Programming to a Transportation Problem of an optimal control model for capital asset management", Journal of the Nigerian Society of Physical Sciences 1 (2019) 116. 